\title{
Weight Minus Extracellular Fluid as Metabolic Reference Standard in Newborn Baby
}

\author{
OMKAR N. BHAKOO^ and JON W. SCOPES \\ From The Neonatal Research Unit, Institute of Child Health (London University), Hammersmith Hospital, London
}

\begin{abstract}
Bhakoo, O. N., and Scopes, J. W. (1971). Archives of Disease in Childhood, 46, 483. Weight minus extracellular fluid as metabolic reference standard in newborn baby. In 51 babies of differing size and gestational age, rates of oxygen consumption and corrected bromide space (as a measure of extracellular fluid) were measured. The results are used to examine the concept that weight minus extracellular fluid (ECF) is an appropriate metabolic reference standard in the newborn baby. When the whole group, which included large-for-dates and smallfor-dates babies, is considered there is a systematic variation wherein the rate of oxygen consumption thus expressed varies with size. However, when appropriately grown babies only are considered, who varied in birthweight from $1210 \mathrm{~g}$ to $3820 \mathrm{~g}$, rates of oxygen consumption thus expressed were constant. The implication is that when unusual rates of oxygen consumption per kilogram body weight are found, they should be interpreted bearing in mind the possibility of an unusual proportion of ECF in the baby. An incidental finding was that small-for-dates babies have a relatively large corrected bromide space.
\end{abstract}

When minimal rates of oxygen consumption are compared between mammals of differing size, whether within a species or comparing one species with another, a general rule emerges; the resting metabolism expressed per unit weight is higher in small animals than in large (Kleiber, 1947). In the human baby there is a 'neonatal violation' of this rule in that the small preterm baby has a lower resting metabolic rate than his larger term fellow. Clearly one explanation of this discrepancy is that weight alone is an inappropriate metabolic reference standard. Use of surface area or weight raised to a power of less than unity (such as 0.73 ) (Kleiber, 1947) merely aggravates the difference in the human newborn (Sinclair, Scopes, and Silverman, 1967). These authors proposed an hypothesis that some account should be taken of the body composition of babies of different size and gestation, and that if absolute values of oxygen consumption were related not to weight but to weight minus extracellular fluid (ECF) (thus, as it were, allowing for the 'wateriness' of pre-term babies) one would find that resting metabolic rates would be the same for preterm small infants and term normal-sized infants.

\footnotetext{
Received 3 February 1971.

^Present address: Department of Pediatrics, Postgraduate Institute of Medical Education and Research, Chandigarh, India.
}

Using measured rates of oxygen consumption and estimated ECF values, Sinclair et al. (1967) found this to be true. However, the definitive study in which both metabolic rates and ECF were measured in the same infant was needed to confirm or refute this prediction. The main purpose of this study is to report measured resting metabolic rate and bromide space in newborn infants. A by-product of the study is data on ECF spaces in babies of varying weight and gestation including small-fordates infants.

\section{Materials and Methods}

Babies. The 51 babies were asymptomatic infants aged 3 to 7 days in the lying-in wards or the neonatal ward of Hammersmith Hospital, of birthweight between $1210 \mathrm{~g}$ and $4420 \mathrm{~g}$ and gestational age between 28 weeks and 423 weeks. Gestational age was calculated from the first day of the mother's last menstrual period in all but 3 cases. In these 3 cases, all of whom were small-for-dates, the mother was uncertain of her dates and gestational age was assessed by physical and neurological characteristics (Robinson, 1966).

In each case, the procedure was explained to the mother and her permission obtained. Care was taken to exclude infants of mothers who had been given iodides.

The babies have been described in 3 groups: (1) those 
above the 90th centile of weight for gestational age (large-for-dates, LFD), (2) those less than the 10th centile (small-for-dates, SFD), and (3) those between the 10th and 90th centiles (appropriate for dates, AFD). The centile tables used were those devised by the Birthday Trust Survey for English babies (Butler and Alberman, 1969). The SFD group did not include any babies in whom there was clinical suspicion of intrauterine infection or of chromosomal abnormality.

Procedure. Sodium bromide in a solution $20 \mathrm{mg}$ / $\mathrm{ml}$ was administered orally, usually by gavage, about $1 \frac{1}{2}$ hours after the previous feed. Any baby who failed to take the full dose or who regurgitated or vomited was excluded from the study. The dose given was $80 \mathrm{mg}$ sodium bromide per $\mathrm{kg}$ body weight. 3 to 5 hours later 1.5-2 ml of blood was taken by heel-prick into a heparinized tube. Rates of oxygen consumption were measured on the same working day, usually after the following feed.

Measurement of oxygen consumption. Rates of $\mathrm{O}_{2}$ consumption were measured in postprandial sleep by a closed circuit method (Scopes and Ahmed, 1966a) with the child lying undisturbed on a small stretcher. The environmental temperature chosen was in the neutral range for a baby of his particular size and gestation (Scopes and Ahmed, 1966b), and this was confirmed by ensuring that the skin temperature of the exposed abdominal wall was about $36^{\circ} \mathrm{C}$. Measurements were made over a 20-30 minute period when the child was asleep and inactive, and are reported as $\mathrm{ml}$ dry gas at $0^{\circ} \mathrm{C}$ and $760 \mathrm{mmHg}$.

Bromide estimation. The blood specimen was centrifuged at once, and the plasma separated and stored at $-20^{\circ} \mathrm{C}$ until estimation. The chemical method of Hunter (1953) was used with strict adherence to his procedure. Known standards, including a specimen of the bromide solution given orally were run at the same time. Bromide determinations were performed in duplicate on 0.25 to $0.5 \mathrm{ml}$ plasma, and the mean of the duplicate was used for calculation. In 43 cases, the chemical duplicates were within 5\% of each other; in terms of the final calculation of percentage of ECF in the baby the difference of the duplicates was less than $\pm 1 \%$ of the mean. In 8 cases it was greater, the variation being $\pm 1.5 \%, 1 \cdot 8 \%, 2 \%, 2.5 \%$, $3 \%, 3.5 \%$, and $4 \%$ of the mean, respectively. In 7 recovery experiments using $30 \mu \mathrm{g}$ bromide, added to $66 \mu \mathrm{g}$ bromide, recovery rates varied from $98-105 \%$.

Bromide space. This was calculated as a corrected bromide space according to the formula:

$$
\frac{\text { mg bromide administered }}{\text { plasma bromide }(\mathrm{mg} / \text { litre })} \times \frac{0.9}{0.95 \times 0.94}
$$

The assumed correction factors are 0.9 for leakage of bromide into RBC, $\mathbf{0 . 9 5}$ for the Donnan factor, and 0.94 for serum water (Cheek, 1961).

\section{Results}

Details of the babies together with their corrected bromide spaces and rates of oxygen consumption are given in Table $I$. All the parameters examined and illustrated in the figures were calculated from the data in this Table. There were no significant differences between studies on days $3,4,5,6$, or 7 in any group with respect to $\mathrm{Vo}_{2}$ or percentage of ECF and so results are considered together. Also there was no significant difference between breastfed and bottle-fed babies in these respects.

Extracellular fluid (corrected bromide space (CBS)). Table II shows the mean value for the 3 groups of babies. The ECF is a higher proportion of the body weight in small-for-dates infants than in the other two groups (AFD v. SFD diff. $=4 \cdot 43$, $P=0.021$ for $40 \mathrm{~d}$. f.). There was no significant difference between appropriate-for-dates infants and large-for-dates infants; however, there were no preterm infants in the large-for-dates group.

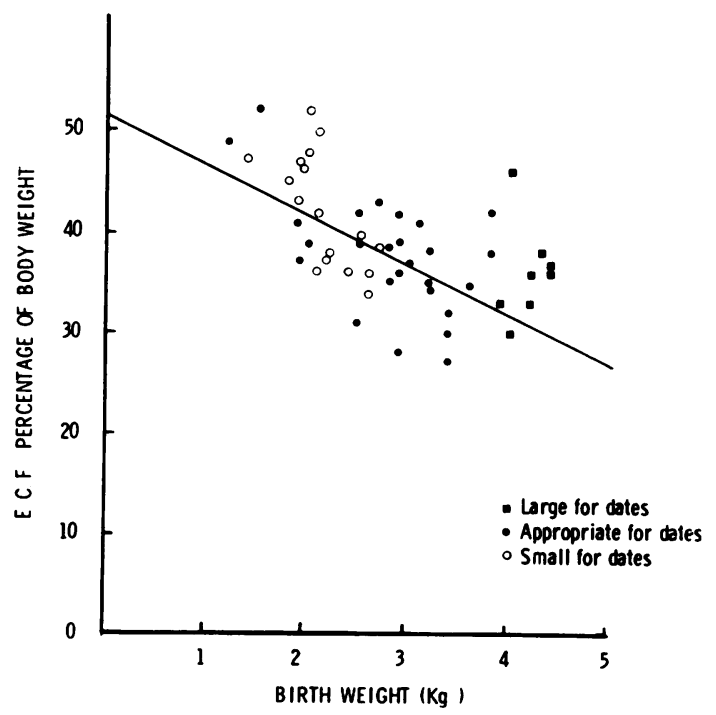

FIG. 1.-Relation of birthweight to percentage of corrected bromide space. Calculated regression equation (appropriate-for-dates only): $y-37 \cdot 7=-4 \cdot 9(x-2 \cdot 8), r=$ $-0.56 P=0.0015$. Calculated regression equation (all groups): $y-38.9=-3.9 \quad(x-2 \cdot 8), \quad r=0.55$ $P<0.0001$.

The individual values are shown in more detail in Fig. 1 where the ECF as a percentage of body weight is plotted against body weight. There is a diminishing percentage with increasing body weight 
TABLE I

Birthweight, Gestation, Oxygen Consumption, and Extracellular Fluid in Babies Studied

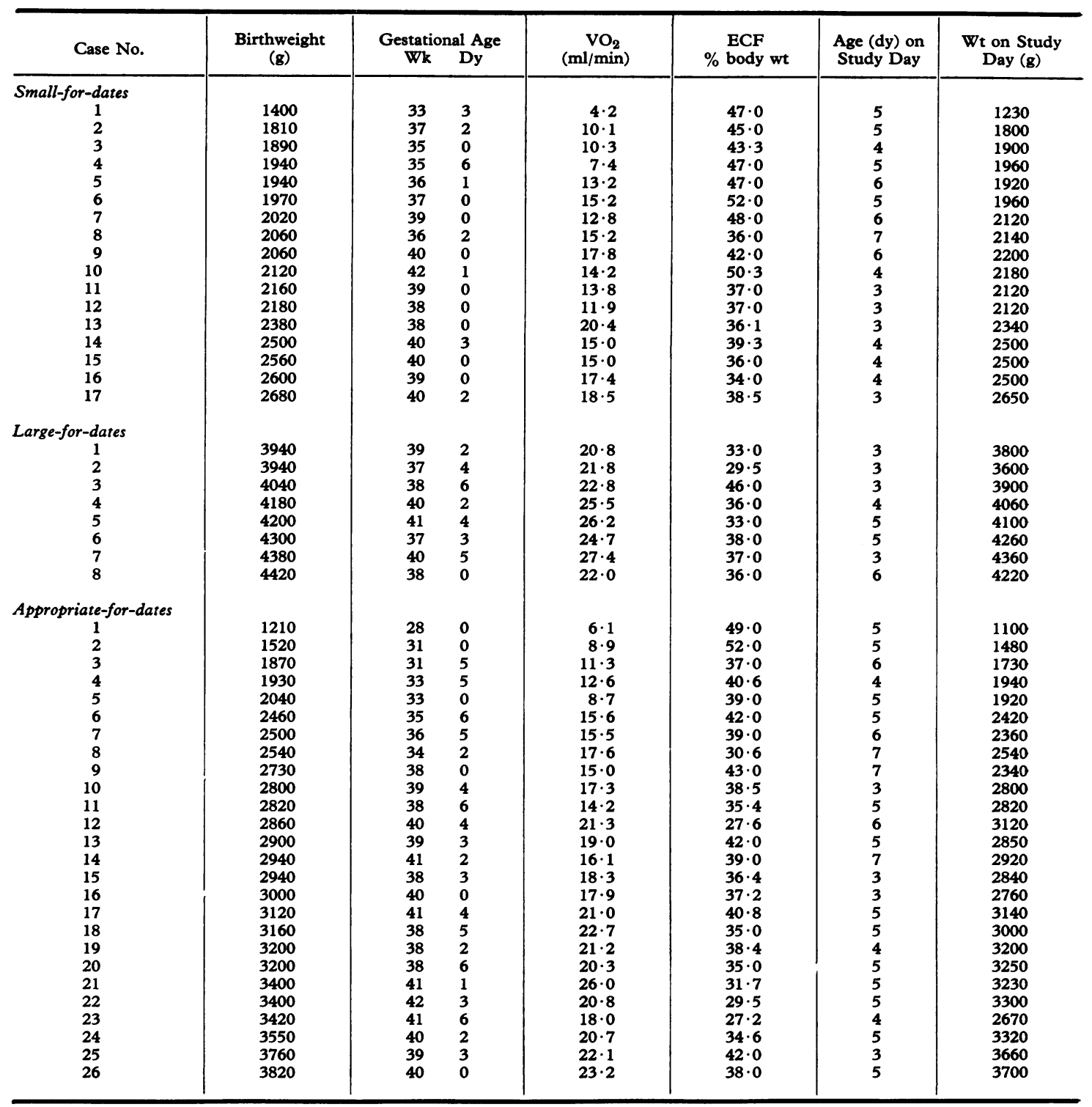

as there is with increasing gestation (Fig. 2). In each case there is a significant correlation between the variables, but the scatter about the line is large.

Fig. 3 shows absolute values of ECF plotted against birthweight where there is a steady rise with increasing weight. Similar plotting of total ECF against gestation merely shows that small-for- dates babies are small (and have a small total ECF) and the reverse is true for large-for-dates babies.

Rates of oxygen consumption. The total rates of oxygen consumption are given in Table $I$ and shown graphically in Fig. 4. Fig. 5 shows rates of oxygen consumption expressed as $\mathrm{ml} / \mathrm{kg}$ per min against birthweight, and the line drawn is 


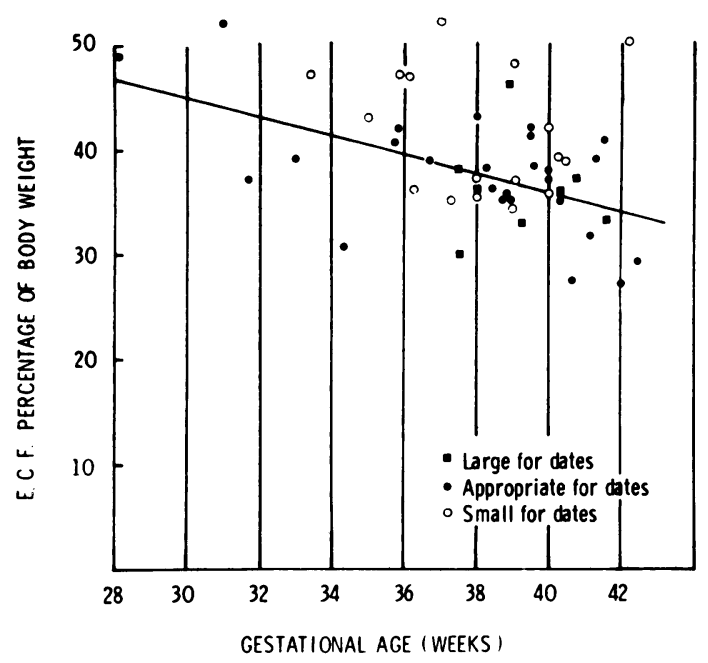

FIG. 2.-Relation of gestational age to percentage of corrected bromide space. Calculated regression equation (appropriate-for-dates only): $y-37 \cdot 7=-0.92(x-38)$, $r=-0.59 P<0.001$. Calculated regression equation (all groups): $y-38 \cdot 9=-0.84(x-38), r=-0.425$ $P<0.001$.

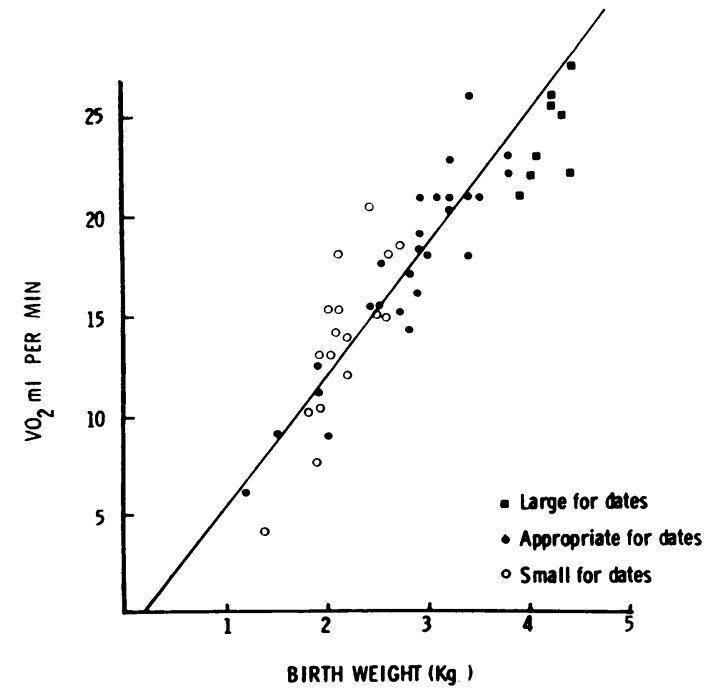

FIG. 4.-Relation of rates of oxygen consumption to birthweight. Calculated regression equation: $y-17 \cdot 4=$ $6 \cdot 7 !(x-2 \cdot 81), r=0.91 P<0.0001$.

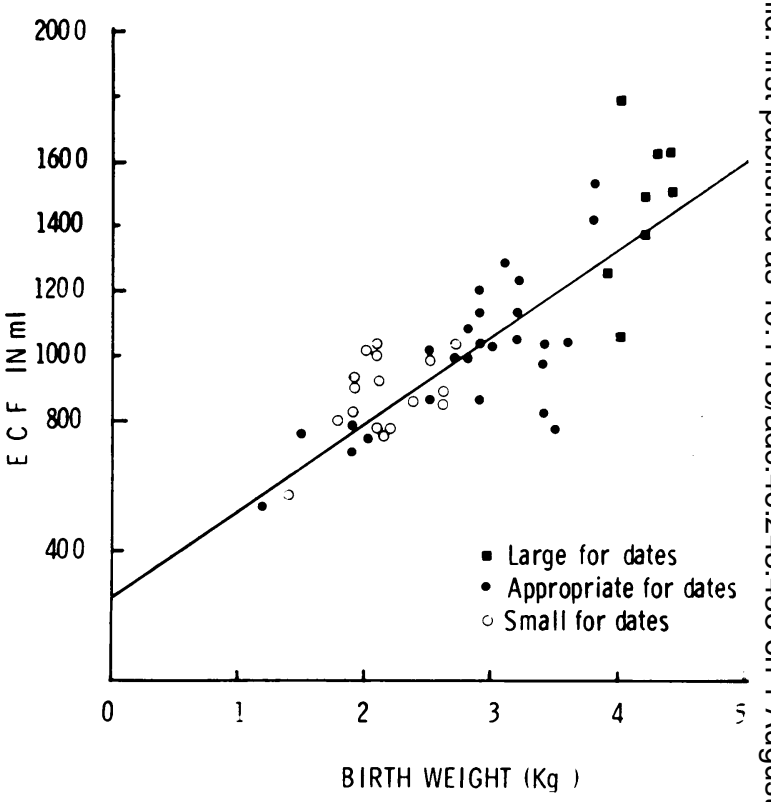

FIG. 3.-Changes in corrected bromide space related to birthweight. Calculated regression equation (appropriatefor-dates only): $y-1001=266 \quad(x-2 \cdot 8), \quad r=0.79$ $P<0 \cdot 0001$. Calculated regression equation (all groups): $y-1033=275(x-2.8), r=0.85 P<0.0001$

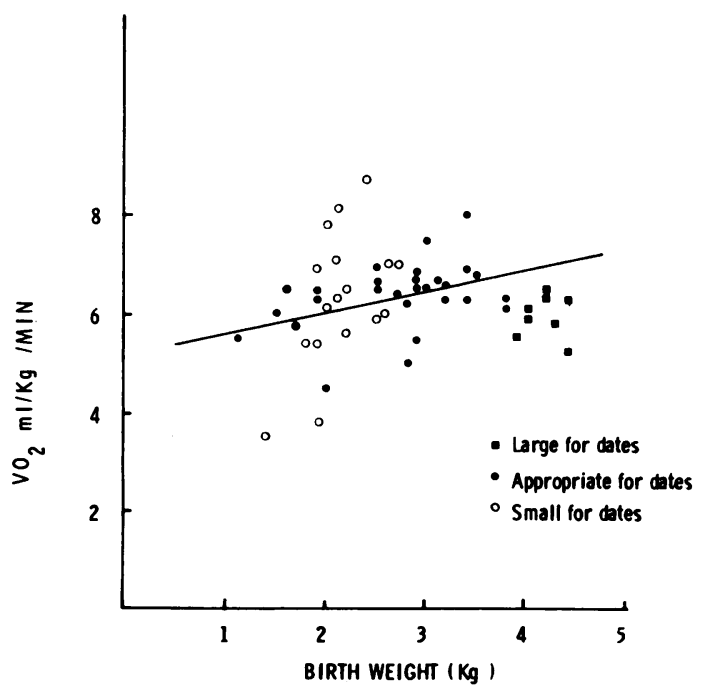

FIG. 5.-Minimal rates of oxygen consumption expressed per unit body weight related to birthweight. Calculated regression equation: $y-6 \cdot 38=0.44(x-2 \cdot 8), r=0.41$ $P=0.0187$. 
TABLE II

Gestational Ages and Corrected Bromide Spaces (as a percentage of body weight) in Three Groups of Babies

\begin{tabular}{|c|c|c|c|c|c|c|}
\hline \multicolumn{3}{|c|}{$\begin{array}{c}\text { Gestation Period } \\
\text { (wk) }\end{array}$} & \multirow{2}{*}{$\begin{array}{l}\text { Group } \\
\text { (No.) }\end{array}$} & \multicolumn{3}{|c|}{$\begin{array}{c}\text { Corrected Bromide } \\
\text { Space \% of Birthweight }\end{array}$} \\
\hline SEM & SD & Mean & & Mean & SD & SEM \\
\hline $\begin{array}{l}0.7 \\
0.5 \\
0.5\end{array}$ & $\begin{array}{l}3 \cdot 7 \\
1 \cdot 5 \\
2 \cdot 3\end{array}$ & $\begin{array}{l}37 \cdot 8 \\
39 \cdot 2 \\
38 \cdot 1\end{array}$ & $\begin{array}{l}\text { AFD (26) } \\
\text { LFD (8) } \\
\text { SFD (17) }\end{array}$ & $\begin{array}{l}37 \cdot 7 \\
36 \cdot 1 \\
42 \cdot 1\end{array}$ & $\begin{array}{l}5 \cdot 8 \\
4 \cdot 9 \\
5 \cdot 7\end{array}$ & $\begin{array}{l}1 \cdot 1 \\
1 \cdot 7 \\
1 \cdot 4\end{array}$ \\
\hline
\end{tabular}

Abbreviations: AFD = appropriate-for-dates.

LFD = large-for-dates.

SFD = small for datcs.

$\mathrm{SD}=$ standard deviation.

SEM = standard error of the mean.

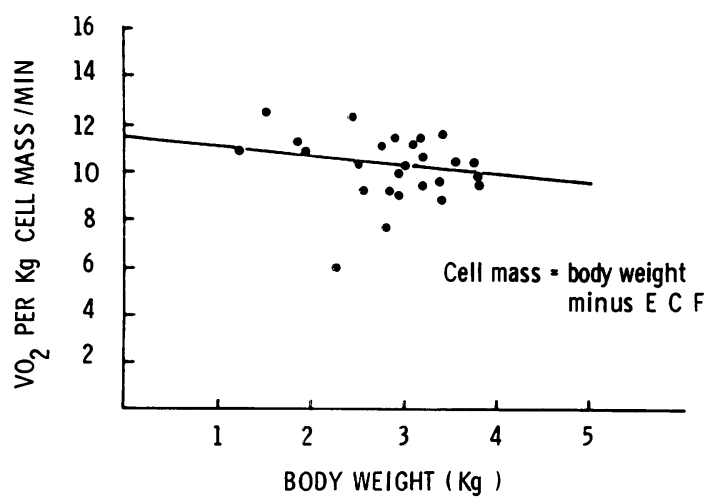

Fig. 6.-Rates of oxygen consumption expressed per unit (weight minus $C B S$ ) related to body weight in appropriatefor-dates babies. Calculated regression equation: $y-$ $10 \cdot 4=-0 \cdot 36(x-2 \cdot 8), r=-0 \cdot 19 P=0 \cdot 18$.

the calculated regression line for appropriate-fordates babies. There is a significant correlation $(\mathrm{r}=0.41, \mathrm{P}<0.02)$ whereby smaller babies have a lower rate of oxygen consumption when expressed thus.

When rates of oxygen consumption are expressed per unit of 'cell mass', i.e. body weight minus ECF, as proposed by Sinclair et al. (1967), there is no significant correlation with weight if appropriate-for-dates babies only are used (Fig. 6) $(r=-0 \cdot 19, P=0 \cdot 18)$. However, when all babies are included (Fig. 7) there is a small but significant negative correlation $(r=-0.24, P=0.0444)$. It is noteworthy that the variation around the line is not materially reduced by using this reference standard rather than weight (compare with Fig. 5).

When rates of oxygen consumption are plotted (Fig. 8) against weight minus ECF and compared with Fig. 4, it is perhaps noteworthy that the small for-dates babies are more evenly distributed about

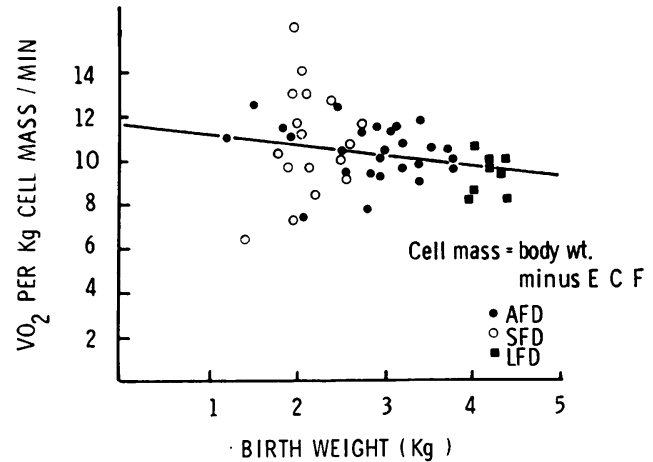

FIG. 7.-Rates of oxygen consumption expressed per unit (weight minus CBS) related to body weight (all groups). Calculated regression equation: $y-10 \cdot 3=0 \cdot 5(x-2 \cdot 8)$, $r=-0.24 P=0.044$.

the line in Fig. 8 where the correlation coefficient is fractionally higher; but the scatter about the line is not significantly different, a finding that is not surprising since total weight and cell mass are closely correlated ( $r=0.925$, Fig. 9).

\section{Discussion}

The conclusions to be drawn from a study such as this depend on the validity of the assumption that corrected bromide space represents ECF.

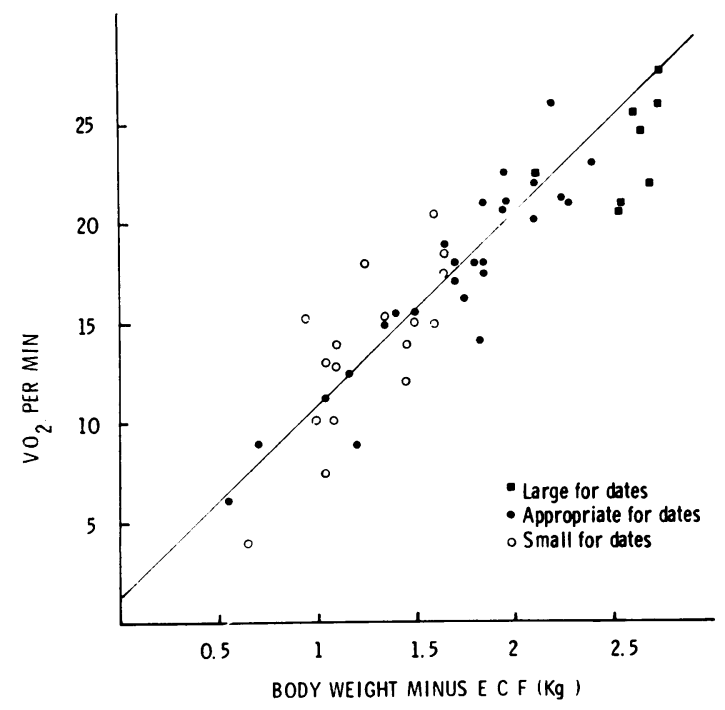

Fig. 8.-Relation of rates of oxygen consumption to cell mass (i.e. body weight minus $C B S$ ). Calculated regression equation: $y-17.4=0.0094(x-1702), r=0.92, P$ $<0 \cdot 0001$. 


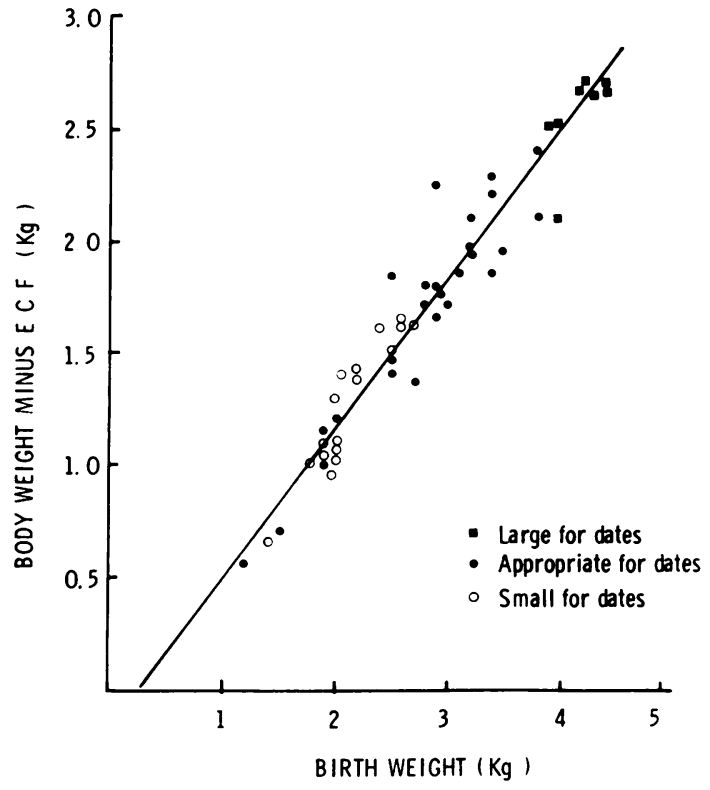

FIG. 9.-The growth of cell mass (i.e. body weight minus $C B S$ ) with increasing weight. Calculated regression equation: $y-1693=659(x-2.8) r=0.96 P<0.0001$.

This assertion is made and defended by a number of distinguished workers (Cheek, 1961; MacLaurin, 1966; O'Brien, Ibbott, and Rodgerson, 1968) but there is no absolute standard whereby it can be finally substantiated. For instance, the thiocyanate space is slightly but significantly larger in babies (compare Friis-Hansen, 1956) and the estimates made by Sinclair et al. (1967) of chloride space (from known figures of carcass analysis) are very much higher than the figures from the present study. Indeed, the major discrepancy between their predictions and our findings are related to the size of the ECF pool which they derived from an uncorrected chloride space. It may be that the serum water of small-for-dates babies would be different from 0.94 and the correction factor of $10 \%$ for bromide entering red blood cells is quite inappropriate for small-for-dates babies who are known to have a high haematocrit (Humbert et al., 1969).

If the appropriate factor were larger, it would vitiate both our findings and Cassady's (1970) that small-for-dates babies have a relatively large ECF space.

None the less, corrected bromide space was chosen in this study as a measure of ECF: (1) because it is widely accepted and theoretically as sound as possible, and (2) because oral administration of bromide in this dosage is totally innocuous and is followed by stable plasma bromide levels at 3 to 6 hours after administration. The ages 3 to 7 days were chosen because over this period there is no material change in rates of oxygen consumption (Scopes and Ahmed, 1966a; Bhakoo and Scopes, 1970) and because preliminary experiments had shown no significant change in ECF in any group over this period (see above). In addition, this dose of bromide had no effect on minimal rates of oxygen consumption.

Our findings for corrected bromide space are similar to those of other workers (Cheek, 1961; MacLaurin, 1966; Friis-Hansen, 1956) and especially those of Cassady (1970). Like him we found that in small-for-dates babies a significantly larger proportion of body weight was represented by 'extracellular fluid'. The similarity of our findings is particulorly interesting in that his cases were studied in the first 12-24 hours of life, whereas in the present series babies were 3-7 days old, i.e. after feeding. There was no difference between breast-fed and formula-fed babies, despite the fact that the latter were inevitably given a rather higher sodium chloride intake.

The percentage of body weight occupied by ECF measured as corrected bromide space falls with increasing birthweight (Fig. 1) and with increasing gestation (Fig. 2) which is in keeping with the general concept that small preterm infants are more 'watery' than their term fellows. However, though the numbers are small it is noticeable that the points representing large-for-dates infants tends to fall above the mean line in Fig. 1 but about the line in Fig. 2. Thus there is a suggestion not statistically supported on these numbers, that large-for-dates infants have an ECF appropriate to gestation rather than to birthweight. Similarly, inspection of Fig. 1 and 2 leads to the suggestion that small-fordates infants have an ECF appropriate to weight rather than to gestation (with the proviso, discussed above, that the correction for bromide in red cells is appropriate). Cassady (1970) comments on the relatively low corrected bromide space (CBS) in large but normally grown infants. It is noteworthy that in Cassady's series no baby was heavier than $3540 \mathrm{~g}$ and large-for-dates babies were not considered. This series shows a tendency to a high corrected bromide space in large-for-dates babies.

The major objective of this study was to confirm or refute the hypothesis of Sinclair et al. (1970), of which one of us is co-author. When weight minus ECF is used as a reference standard for rates of oxygen consumption and when 
appropriate-for-dates babies only are considered, our data show, as Sinclair et al. (1970) had predicted, that there is no longer a significant relation between metabolic rate thus expressed and body size. To this extent the hypothesis is supported. However, the hypothesis should not exclude small-for-dates or large-for-dates babies, and when all babies are considered together there is a significant negative correlation; furthermore, use of this reference standard does not materially reduce variation. Thus our data do not support the hypothesis that weight minus ECF is a good representation of the theoretical compartment of 'active cell mass'. It is clearly a better approximation than weight or surface area since it serves in appropriate-for-dates babies, but it is far from perfect. A corollary of the hypothesis was the prediction that small-for-dates babies should have a low ECF: neither our data nor that of Cassady (1970) substantiate that prediction, though it may be noted from inspection of the figures that the overall group labelled smallfor-dates is clearly heterogeneous. The compartment described by weight minus ECF shows a difference in quality in which small-for-dates babies have a high rate of oxygen consumption and large-for-dates a low rate. Thus it is in keeping with the general biological rule mentioned in the introduction but not acceptable as a description of 'active cell mass'.

None the less, the concept that metabolic rate is related in a simple proportional way to some fraction of body weight which might be defined in terms of body composition still seems more meaningful than using weight raised to an empirically determined power. Weight raised to the power of say, $1 \cdot 22$, is physiologically meaningless, whereas if a reference standard defined in body composition terms is found to hold true it has important implications. For instance, if weight minus ECF were an accepted reference standard, and one were considering a baby whose rate of oxygen consumption per kilogram was low, one must consider whether the baby was truly hypometabolic or whether the low rate is spurious because of a high ECF. This, we suggest, is in fact the case with the appropriately grown preterm baby, and this sort of reference standard would be useful in interpreting rates of oxygen consumption in malnourished oedematous infants (though, of course, these particular data do not apply to the latter group).

The finding that weight minus ECF appears to be an appropriate reference standard for appropriatefor-dates babies is interesting because of the implications mentioned above, but these empirical findings do not constitute proof of a physiological truth.
The possibility remains that the empirical fit could be coincidental. None the less, for any reference standard there should be a theoretical reason for expecting it to be appropriate, and it should hold up to empirical testing in subjects of different size. The further requirement that it should be expected to reduce variation has not been substantiated in these data.

In conclusion, we should emphasize that we do not advocate that ECF need be estimated in every baby in order to decide whether a rate of oxygen consumption is within normal limits. Using weight as a standard and a regression line for reference remains a reasonable practical way to assess a metabolic rate. Our data, and the theoretical background, however, suggest that for any meaningful interpretation of unusual findings, the possibility of an unusual proportion of ECF should be considered.

O. N. Bhakoo held a fellowship from the Ministry of Overseas Development during this study. The authors are also grateful to the Wellcome Foundation, to the Trustees of the Sir William Coxon Trust Fund for provision of laboratory facilities, and to Professor J. P. M. Tizard and Dr. R. J. Robinson for help in the preparation of this paper.

\section{REFERENCES}

Bhakoo, O. N., and Scopes, J. W. (1970). Minimal rates of oxygen consumption in small-for-dates newborn babies. Paper to Paediatric Research Society, April, 1970. (Abst.) Archives of Disease in Childhood, 45, 712. (To be published in full.)

Butler, N. R., and Alberman, E. D. (1969). (Editors.) Perinatal Problems: The Second Report of the 1958 British Perinatal Mortality Survey. Livingstone, Edinburgh.

Cassady, G. (1970). Bromide space studies in infants of low birthweight. Pediatric Research, 4, 14.

Cheek, D. B. (1961). Extracellular volume: its structure and measurement and the influence of age and disease. Fournal of Pediatrics, 58, 103.

Friis-Hansen, B. (1956). Changes in body water compartments during growth. Acta Paediatrica, 46, suppl. 110.

Humbert, J. R., Abelson, H., Hathaway, W. E., and Battaglia, F. C. (1969). Polycythemia in small for gestational age infants. fournal of Pediatrics, 75, 812.

Hunter, G. (1953). Bromide determination in body fluids. Biochemical fournal, 54, 42.

Kleiber, M. (1947). Body size and metabolic rate. Physiological Reviews, 27, 511 .

MacLaurin, J. C. (1966). Changes in body water distribution during the first two weeks of life. Archives of Disease in Childhood, 41, 286.

O'Brien, D., Ibbott, F. A., and Rodgerson, D. O. (1968). Laboratory Manual of Pediatric Micro-biochemical Techniques, p. 78. 4th ed. Harper and Row, New York.

Robinson, R. J. (1966): Assessment of gestational age by neurological examination. Archives of Disease in Childhood, 41, 437.

Scopes, J. W., and Ahmed, I. (1966a). Minimal rates of oxygen consumption in sick and premature newborn infants. Archives of Disease in Childhood, 41, 407.

Scopes, J. W., and Ahmed, I. (1966b). Range of critical temperatures in sick and premature newborn babies. Archives of Disease in Childhood, 41, 417.

Sinclair, J. C., Scopes, J. W., and Silverman, W. A. (1967). Metabolic reference standards for the neonate. Pediatrics, 39, 724.

Correspondence to Dr. Jon W. Scopes, Institute of Child Health (University of London), Hammersmith Hospital, London W.12. 